\title{
Implementing a Population Health Management Intervention to Control Cardiovascular Disease Risk Factors
}

\author{
Shelley A. Jazowski, MPH ${ }^{1,2}$, Hayden B. Bosworth, $P h D^{1,3,4,5,6}{ }_{\mathbb{D}}$, \\ Karen M. Goldstein, MD, MSPH ${ }^{3,4}$, Courtney White-Clark, MS ${ }^{3}$, Felicia McCant, MSSW ${ }^{3}$, \\ Jennifer M. Gierisch, $P h D^{1,7}$, and Leah L. Zullig, MPH, $P h D^{1,3}$
}

\begin{abstract}
'Department of Population Health Sciences, Duke University School of Medicine, Durham, NC, USA; ${ }^{2}$ Department of Health Policy and Management, University of North Carolina at Chapel Hill, Chapel Hill, NC, USA; ${ }^{3}$ Center of Innovation to Accelerate Discovery and Practice Transformation, Durham Veterans Affairs Health Care System, Durham, NC, USA; ${ }^{4}$ Division of General Internal Medicine, Duke University School of Medicine, Durham, NC, USA; 5 School of Nursing, Duke University, Durham, NC, USA; ${ }^{6}$ Department of Psychiatry and Behavioral Sciences, Duke University, Durham, NC, USA; ${ }^{7}$ Department of Medicine, Duke University School of Medicine, Durham, NC, USA.
\end{abstract}

J Gen Intern Med 35(6): 1931-3

DOI: $10.1007 / \mathrm{s} 11606-020-05679-4$

(c) Society of General Internal Medicine 2020

\section{INTRODUCTION}

Patient- (e.g., health literacy), provider- (e.g., clinical inertia), and system-level (e.g., under-empowered care teams) barriers have contributed to suboptimal cardiovascular disease (CVD) risk management among US Veterans. ${ }^{1}$ Among Veterans using the Veterans Health Administration (VHA), more than $80 \%$ have at least two CVD risk factors, ${ }^{2}$ with approximately $34 \%$ and $49 \%$ having a diagnosis of hypertension and dyslipidemia, respectively. ${ }^{3}$ Innovative care delivery models that use patientgenerated health data, integrate non-physician providers into the primary care team, and facilitate patient-provider interaction have the potential to control CVD risk factors at the individual- and population-level. ${ }^{4}{ }^{5}$ Therefore, the objective of the Team-supported, Electronic health record (EHR)-leveraged, Active Management (TEAM) pilot study was to assess the feasibility of a multi-component CVD risk management intervention among Veterans in rural North Carolina.

\section{METHODS}

TEAM consisted of the following steps: (1) population health manager (PHM) reviewed clinical data and used established algorithms to identify adults (aged 18-79) with uncontrolled blood pressure (systolic blood pressure $>$ $140 \mathrm{mmHg}$ ) and/or meeting criteria for, but not prescribed, statin therapy; (2) patients identified by the PHM received a letter which communicated patient-specific CVD risk and associated health implications, self-management strategies, and topics to discuss with their primary care team; (3) PHM entered care plan (detailed CVD risk profile, clinical guidelines, and treatment recommendations) in the EHR to

Received August 30, 2019

Accepted January 23, 2020

Published online February 3, 2020 facilitate treatment discussions between patients and their primary care team at the point of care; (4) primary care team member(s) ordered treatment (pharmaceutical or behavioral) as appropriate; and (5) PHM monitored and reported patients' progress.

We reviewed EHRs at 45 and 90 days after the intervention to document changes in blood pressure and to identify Veterans' engagement with the healthcare system (e.g., scheduled/attended appointments).

\section{RESULTS}

Over 4 months, 100 Veterans received personalized CVD risk letters, of which 46 received a letter prior to their primary care appointment and 54 received a letter without having a scheduled appointment (Table 1). In the 90 days following the intervention, $83 \%$ (38/46) of patients attended scheduled appointments and $61 \%(33 / 54)$ of Veterans who did not have an appointment at the time of the letter scheduled one. Notably, $62 \%(62 / 100)$ of Veterans contacted a healthcare provider to check their blood pressure, modify their medications, or obtain a referral for another health service (e.g., smoking cessation program).

Responding to healthcare provider and patient recommendations, the letter was modified to better inform patients of their immediate CVD risk (blood pressure was used instead of Atherosclerotic Cardiovascular Disease Risk Score). In the 45 days following receipt of the revised intervention, $40 \%$ $(20 / 50)$ of Veterans had blood pressure measurements $<140$ / $90 \mathrm{mmHg}$ (Table 2). Compared with baseline, 45-day systolic blood pressure and diastolic blood pressure decreased an average $11 \mathrm{mmHg}$ and $5 \mathrm{mmHg}$, respectively.

\section{DISCUSSION}

TEAM was a relatively low-touch intervention that used tailored messaging to communicate CVD risk and empowered an existing non-physician provider as a PHM. These factors 
Table 1 Characteristics of Veterans Who Received a Cardiovascular Disease Risk Letter

\begin{tabular}{|c|c|c|}
\hline$\overline{\text { Characteristic** }}$ & Received original letter $(n=100)$ & Received revised letter $(n=50)^{\dagger}$ \\
\hline \multicolumn{3}{|l|}{ Demographics } \\
\hline Age (mean, SD) & $61.92(8.47)$ & $64.34(10.26)$ \\
\hline \multicolumn{3}{|l|}{$\operatorname{Sex}(N, \%)$} \\
\hline Male & $88(88)$ & $44(88)$ \\
\hline Female & $12(12)$ & $6(12)$ \\
\hline \multicolumn{3}{|l|}{ Race/ethnicity $(N, \%)$} \\
\hline White & $27(27)$ & $16(32)$ \\
\hline Black & $71(71)$ & $33(66)$ \\
\hline Pacific Islander & $0(0)$ & $1(2)$ \\
\hline Native Hawaiian & $1(1)$ & $0(0)$ \\
\hline Declined to answer & $1(1)$ & $0(0)$ \\
\hline \multicolumn{3}{|l|}{ Clinical characteristics } \\
\hline Baseline SBP (mean, SD) & $156.22(14.11)$ & $153.96(11.38)$ \\
\hline Baseline DBP (mean, SD) & $87.72(11.11)$ & $83.60(9.38)$ \\
\hline 45-day SBP (mean, SD) & N/A & $142.74(18.56)$ \\
\hline 45-day DBP (mean, SD) & N/A & $78.50(9.12)$ \\
\hline ASCV̌D Risk Score (mean, SD) & $37.23(21.07)$ & N/A \\
\hline BMI (mean, SD) & $31.19(7.94)$ & N/A \\
\hline Tobacco use $(N, \%)$ & $36(36)$ & $16(32)$ \\
\hline Diabetes $(N, \%)$ & $36(36)$ & $35(70)$ \\
\hline \multicolumn{3}{|l|}{ Intervention and health system engagement } \\
\hline Letter sent prior to scheduled appointment & $46(46)$ & $0(0)$ \\
\hline Letter sent without scheduled appointment & $54(54)$ & $50(100)$ \\
\hline Interacted with PHM & $68(68)$ & $31(62)$ \\
\hline Appointment attended ${ }^{\ddagger}$ & $38(83)$ & $0(0)$ \\
\hline Appointment scheduled ${ }^{\S}$ & $33(61)$ & $46(92)$ \\
\hline
\end{tabular}

ASCVD, atherosclerotic cardiovascular disease; BMI, body mass index; DBP, diastolic blood pressure; PHM, population health manager, SBP, systolic blood pressure; $S D$, standard deviation

*Patient characteristics and health system engagement were collected from electronic health records

$\uparrow$ Based on healthcare provider and patient recommendations, the letter was modified to better inform patients of their cardiovascular disease (CVD) risk. Since blood pressure was used instead of ASCVD risk, BMI and ASCVD risk scores were not collected for this cohort

$\$$ The percentage of Veterans who attended scheduled primary care appointment was based on the number of those $(n=46)$ who received a CVD risk letter prior to their scheduled primary care appointment

$\S$ The percentage of Veterans who scheduled a primary care appointment was based on the number of those $(n=54)$ who received a CVD risk letter without having a primary care appointment scheduled

prompted patient engagement with the healthcare system and improvements in both systolic and diastolic blood pressure. As the primary care infrastructure is increasingly stretched thin, this two-pronged approach may be a sustainable solution to address uncontrolled CVD risk factors for it promotes patients' awareness and management of their CVD risk and enables a single member of the primary care team to oversee a large patient panel.

Limitations included a predominantly male patient population; thus, we were unable to account for potential gender differences in CVD risk management and health-seeking behaviors. Additionally, we used a pre/post study design without a control group and could not discern which intervention component(s) drove observed clinical and behavioral changes. Lastly, our study focused on rural Veterans receiving care at an

Table 2 Baseline and 45-Day Blood Pressure Measurements

\begin{tabular}{lll}
\hline \hline $\begin{array}{l}\text { Blood pressure } \\
\text { category* }\end{array}$ & $\begin{array}{l}\text { Baseline blood } \\
\text { pressure }\end{array}$ & $\begin{array}{l}\text { Follow-up blood } \\
\text { pressure }\end{array}$ \\
\hline $\mathrm{BP}<140 / 90$ & 0 & 20 \\
$140 / 90<\mathrm{BP}<150 / 90$ & 14 & 8 \\
$150 / 90<\mathrm{BP}<160 / 90$ & 27 & 5 \\
$\mathrm{BP}>160 / 90$ & 9 & 9 \\
\hline
\end{tabular}

$B P$, blood pressure

*Blood pressure values were collected from electronic health records and are reported for the 50 Veterans who received the revised cardiovascular disease (CVD) risk letter integrated healthcare system, which limits generalizability to other healthcare settings.

Despite these limitations, our study has important clinical implications. First, personalized CVD risk letters have the potential to educate a large population of at-risk patients and thus increase patient self-management and participation in healthcare decision-making. Second, interactions with a PHM may ensure patients are prepared to discuss treatment options with their provider, therefore resulting in timely treatment initiation or intensification. Finally, engaging existing non-physician providers as PHMs may reduce the burden of primary care physicians and thus allow them to focus on more complex cases.

Acknowledgments: We thank the Center of Innovation to Accelerate Discovery and Practice Transformation (ADAPT) at the Durham Veterans Affairs Health Care System for their support.

Corresponding Author: Hayden B. Bosworth, PhD; Department of Psychiatry and Behavioral Sciences Duke University, Durham, NC, USA (e-mail: boswo001@duke.edu).

Funding Information The research reported in this publication was financially supported by the Office of Rural Health Award (OHR 14379). Drs. Zullig and Goldstein were financially supported by VA Health Service Research and Development (HSR\&D) Career Development Awards (CDA 13-025; 13-263, respectively). Dr. Bosworth was financially supported by a Research Career Scientist award from VA HSR\&D (VA HSR\&D 08-027). 


\section{Compliance with Ethical Standards:}

Conflict of Interest: Ms. Jazowski, Ms. McCant, Ms. White-Clark, and Drs. Goldstein and Gierisch report no conflicts of interest. Dr. Bosworth reports research grants from Sanofi, PhRMA Foundation, Proteus Digital Health, Otsuka, Novo Nordisk, Improved Patient Outcomes, as well as consulting from Novartis, Abbott, and Sanofi. Dr. Zullig reports research grant support from the PhRMA Foundation and Proteus Digital Health, as well as consulting from Novartis.

Disclaimer: The content is solely the responsibility of the authors and does not necessarily reflect the position or policy of Duke University, the US Department of Veterans Affairs, or the US government.

\section{REFERENCES}

1. Borzecki AM, Oliveria SA, Berlowitz DR. Barriers to hypertension control. Am Heart J. 2005;149(5):785-94.
2. Richlie DG, Winters S, Prochazka AV. Dyslipidemia in Veterans: multiple risk factors may break the bank. Arch Intern Med. 1991;151(7):1433-36.

3. Fryar CD, Herrick K, Afful J, Ogden CL. Cardiovascular disease risk factors among male Veterans, U.S., 2009-2012. Am J Prev Med. 2016;50(1):101-05.

4. Milman T, Joundi RA, Alotaibi NM, Saposnik G. Clinical inertia in the pharmacological management of hypertension: a systematic review and meta-analysis. Medicine (Baltimore). 2018;97(25):e11121.

5. Russell-Jones D, Pouwer F, Khunti K. Identification of barriers to insulin therapy and approaches to overcoming them. Diabetes Obes Metab. 2018;20(3);488-496.

Publisher's Note Springer Nature remains neutral with regard to jurisdictional claims in published maps and institutional affiliations. 